\title{
APROVEITAMENTO DA TORTA DA AMÊNDOA DA MACAÚBA (Acrocomia aculeata) PARA PRODUÇÃO DE BISCOITO TIPO "COOKIE".
}

\author{
A. L. M. SILVEIRA ${ }^{1}$, L. A. L. QUEIROZ ${ }^{1}$, R. M. FONSECA ${ }^{1}$, N. de C. TEIXEIRA ${ }^{2}$, A. C. P. A. \\ de MELO $^{2}$, L. H. E. S. LABOISSIÈRE ${ }^{2}$ e M. H. C. ANDRADE ${ }^{3}$ \\ ${ }^{1}$ Universidade Federal de Minas Gerais, Escola de Engenharia, Departamento de Engenharia \\ Química \\ ${ }^{2}$ Universidade Federal de Minas Gerais, Departamento de Alimentos/FAFAR \\ ${ }^{3}$ Departamento de Engenharia Química - Escola de Engenharia - Universidade Federal de Minas \\ Gerais
}

E-mail: analueng@yahoo.com.br

RESUMO - A presença de palmeiras Macaúba (Acrocomia aculeata) no Estado de Minas Gerais é uma constante que gera uma intensa atividade extrativista em diversas regiões do Estado. Principalmente no Norte de Minas Gerais é conhecida a utilização das diversas partes da Macaúba pelo mercado, gerando renda para diversas famílias. Atualmente seus frutos têm sido mais utilizados para obtenção de óleo a partir da polpa e da amêndoa, produzindo uma quantidade apreciável de coprodutos com menor valor comercial, dentre eles, destacam-se as tortas resultantes da extração por prensagem das partes polpa e amêndoa. Com foco na agregação de valor a esses coprodutos, o objetivo deste trabalho foi propor mais uma forma de utilização da torta da amêndoa da Macaúba, que apresentou características nutricionais e sensoriais interessantes para o consumo humano. Nesse sentido, três diferentes fórmulas foram elaboradas para produção de um biscoito tipo "cookie" feito com a torta da amêndoa da Macaúba, com 0\%, 30\% e 60\% de substituição da farinha de trigo pela torta. Os "cookies" com $0 \%, 30 \%$ e $60 \%$ apresentaram as seguintes composições centesimais, respectivamente: umidade, $9,51 \%, 10,34 \%$ e $7,41 \%$; resíduo mineral fixo, 2,32\%, 2,52\% e 2,97\%; proteínas totais, 6,72\%, 6,93\% e 10,27\%; lipídios, 4,88\%, 10,07\% e 13,81\%; fibras, $2,90 \%, 4,58 \%$ e 9,28\%; carboidratos, $76,57 \%, 70,14 \%$ e $65,54 \%$; sódio, 5,28 mg/g, 4,07 mg/g e 4,71 mg/g; valor calórico, 377,08 kcal, 398,91 kcal e 427,53 kcal. Os resultados da análise sensorial indicam que ambas as formulações contendo a torta da amêndoa foram bem aceita pelos provadores indicando a possibilidade de introdução de um novo produto no setor alimentício.

\section{INTRODUÇÃO}

Os óleos vegetais são considerados uma nova opção para o mercado energético. Como consequência, o mercado internacional acirrou a competição entre potenciais exportadores, (Brasil, Estados Unidos, Argentina, Malásia e Indonésia), contribuindo para redução no nível de estoques e uma menor disponibilidade de óleos vegetais, bem como para a sustentação da alta nos 
preços. Nos dias atuais, as principais oleaginosas exploradas são a soja, a palma, e a canola, sendo que a alta de seus preços no mercado internacional não coloca em risco somente a sustentabilidade dos Programas Energéticos, mas também, a segurança alimentar de países mais pobres que são importadores de alimentos (IEA, 2008).

A Macaúba (Acrocomia aculeata) tem-se destacado positivamente como uma palmeira explorada por pequenos produtores e comunidades na extração de seus óleos, sendo utilizada sob o padrão extrativista. Lorenzi (2006) mostra que não somente seus óleos são aproveitados através da polpa e da amêndoa, mas também há um aproveitamento do seu endocarpo para a produção de carvão vegetal, em função de seu alto poder calorífico. A produção de ração animal através do farelo e tortas resultantes da extração dos óleos também evidencia do uso desta palmeira, sendo estas partes ricas em fibras e proteínas. Ainda, salienta-se o aproveitamento de sua madeira, para produção de mourões e estacas, folhas para forragem animal e cobertura de casa e o estipe para produção de palmito.

Com foco no aproveitamento da torta resultante da extração do óleo da amêndoa da Macaúba na alimentação humana, este trabalho desenvolveu um biscoito do tipo cookie, testando sua aceitação através da análise sensorial e analisando sua composição físico-química.

\section{MATERIAL E MÉTODOS}

\subsection{Obtenção da matéria-prima}

Os frutos da Macaúba utilizados deste trabalho foram doados por pesquisadores da Universidade Federal de Viçosa. Foram fornecidos cerca de $250 \mathrm{~kg}$ do fruto, tendo esses sido coletados em janeiro de 2013 e conservados por dois meses em silos com aeração. Na sequência, o processamento desses frutos para a obtenção da amêndoa foi efetuado na empresa DIBIO - Dores do Indaiá Óleos Vegetais (MG). Após processamento, obteve-se a torta da amêndoa da Macaúba, ingrediente necessário para o desenvolvimento dos biscoitos tipo "cookies" elaborados. Destaca-se que a matéria-prima se encontrava adequada ao uso em conformidade a legislação vigente para a obtenção de produtos alimentícios.

\subsection{Desenvolvimento e avaliação sensorial do "cookie" a base de torta de amêndoa da Macaúba}

O biscoito desenvolvido teve a receita original alterada com substituição parcial da farinha de trigo pela torta da amêndoa, baseando-se em produtos semelhantes encontrados na literatura, que efetuam a substituição parcial por farinhas de frutas e legumes diversos. A formulação utilizada para cada "cookie" segue relacionada na Tabela 1.

Avaliou-se a aceitação dos biscoitos tipo cookies produzidos com a torta da amêndoa em relação aos atributos aparência, sabor, textura, aroma e impressão global, usando-se escala hedônica não estruturada medindo dez centímetros, em que as extremidades variavam de "desgostei extremamente" a "gostei extremamente". Para analisar a nota atribuída às amostras pelo consumidor, considerou-se uma casa decimal nas notas e nove pontos na reta que correspondiam aos termos hedônicos conforme descritos na

Tabela 2. 
Tabela 1 - Formulação dos "cookies" com $0 \%, 30 \%$ e $60 \%$ de torta de amêndoa de Macaúba

Ingredientes utilizados: farinha de trigo (FT); torta da amêndoa (TA), açúcar mascavo (AM); açúcar branco $(\mathrm{AB})$; ovo $(\mathrm{O})$; margarina $(\mathrm{M})$; sal $(\mathrm{S})$; fermento $(\mathrm{F})$.

Formulação com 0\% de TA: Formulação com 30\% de TA: Formulação com 60\% de TA:

- $100 \% \mathrm{FT}$

- $44 \% \mathrm{AB}$

- $36 \% \mathrm{AM}$

- $22 \% \mathrm{O}$

- $1,6 \% \mathrm{~S}$

- $8,8 \% \mathrm{~F}$

- $12 \% \mathrm{M}$
- $70 \% \mathrm{FT}$

- $30 \%$ TA

- $44 \% \mathrm{AB}$

- $36 \% \mathrm{AM}$

- $22 \% \mathrm{O}$

- $1,6 \% \mathrm{~S}$

- $8,8 \% \mathrm{~F}$

- $12 \% \mathrm{M}$
- $40 \% \mathrm{FT}$

- $60 \% \mathrm{TA}$

- $44 \% \mathrm{AB}$

- $36 \% \mathrm{AM}$

- $22 \% \mathrm{O}$

- $1,6 \% \mathrm{~S}$

- $8,8 \% \mathrm{~F}$

- $12 \% \mathrm{M}$

Tabela 2 - Distribuição das notas atribuídas pelos provadores no teste de aceitação dos "cookies" com 0\%, $30 \%$ e $60 \%$ de torta de amêndoa de Macaúba.

\begin{tabular}{ccc}
\hline Notas atribuídas & Correspondência & Termo hedônico \\
0 a 1,0 & 1 & Desgostei muitíssimo \\
1,1 a 2,0 & 2 & Desgostei muito \\
2,1 a 3,0 & 3 & Desgostei moderadamente \\
3,1 a 4,0 & 4 & Desgostei ligeiramente \\
4,1 a 4,9 & 5 & Nem gostei e nem desgostei \\
5,0 a 5,9 & 6 & Gostei ligeiramente \\
6,0 a 6,9 & 7 & Gostei moderadamente \\
7,0 a 7,9 & 8 & Gostei muito \\
8,0 a 9,0 & 9 & Gostei muitíssimo \\
\hline
\end{tabular}

Para o teste da intenção de compra usou-se uma escala de atitude, em que as extremidades variavam de "certamente não compraria" a "certamente compraria".

Os testes foram feitos com 120 provadores não treinados, escolhidos aleatoriamente entre alunos, professores e funcionários da UFMG, de ambos os sexos com idade entre 18 e 45 anos, no LASEC - Laboratório de Análise Sensorial e Estudos do Consumidor, situado no Departamento de Alimentos da Faculdade de Farmácia da UFMG. As cabines eram individuais, iluminadas com luz branca para não interferir no julgamento da aparência do produto. 
Foram servidas monadicamente aos provadores três amostras dos biscoitos $(\mathrm{A}, \mathrm{B}, \mathrm{C})$ à temperatura ambiente, adequadamente identificadas por códigos aleatórios de três dígitos, juntamente com um biscoito de água para neutralizar o paladar e um copo de água à temperatura ambiente para enxaguar a boca após cada avaliação e evitar resíduos gustativos de uma amostra a outra.

Para a análise estatística, foi utilizada a análise de variância (ANOVA) com base nos resultados dos testes aplicados. Seguiu-se com Testes de Comparação de Médias de Tukey a um nível de 95\% de confiança (MINIM, 2010).

\subsection{Composição centesimal dos biscoitos tipo cookies}

A composição centesimal do "cookie" foi realizada no laboratório do SENAI - CETEC, no qual foram realizados testes seguindo padrões do Instituto Adolfo Lutz (2208) de umidade a $105^{\circ} \mathrm{C}$, pelo método 12 ; resíduos minerais fixos, pelo método 18 ; proteínas totais, método 37 ; lipídios (extrato etéreo), método 32; fibras, método 44. Os carboidratos e o valor calórico do biscoito foram realizados seguindo os padrões da Tabela TACO (2011).

\section{RESULTADOS E DISCUSSÃO}

$\mathrm{Na}$ 
Tabela 3 são mostrados os resultados da análise físico-química das três formulações de cookies desenvolvidas, com 0\%, 30\% e 60\% de substituição da farinha de trigo pela torta da amêndoa da Macaúba.

Quando se comparam as três formulações, observa-se a influência da torta da Macaúba no teor de proteínas, fibras, carboidratos, lipídios e, consequentemente, no valor calórico.

Os valores de umidade encontrados nos "cookies" com $0 \%$ e $30 \%$ foram semelhantes, sendo de 9,51 e $10,34 \mathrm{~g} / 100 \mathrm{~g}$, respectivamente. O "cookie" com $60 \%$ apresentou um valor de umidade de $7,41 \mathrm{~g} / 100 \mathrm{~g}$. Essa diferença pode ser justificada pela quantidade de fibra presente na amostra com $60 \%$, que representa praticamente o dobro do biscoito com $30 \%$ e o triplo da quantidade presente na amostra sem torta de amêndoa.

O aumento gradativo da quantidade de torta de amêndoa de Macaúba representou uma elevação proporcional na quantidade de proteína e uma diminuição da quantidade de carboidratos, conforme esperado.

Assim, pode-se considerar que a utilização da torta da amêndoa da Macaúba em alimentos, do ponto de vista nutricional, traz benefícios para a saúde humana, quando se considera a necessidade de ingestão de alimentos contendo teores significativos de componentes funcionais para o ser humano, como as fibras e as proteínas. 
Tabela 3- Resultados físico-químicos das três formulações de “cookies”*.

\begin{tabular}{lccc}
\hline \multicolumn{1}{c}{ Parâmetros / unidades } & $0 \%$ & $30 \%$ & $60 \%$ \\
Umidade a $105^{\circ} \mathrm{C} ; \mathrm{g} / 100 \mathrm{~g}$ & 9,51 & 10,34 & 7,41 \\
Resíduo Mineral Fixo; g/100g & 2,32 & 2,52 & 2,97 \\
Proteínas Totais; g/100g & 6,72 & 6,93 & 10,27 \\
Lipídios (Extrato Etéro); g/100g & 4,88 & 10,07 & 13,81 \\
Fibra; g/100g & 2,90 & 4,58 & 9,28 \\
Carboidratos por diferença; g/100g & 76,57 & 70,14 & 65,54 \\
Sódio; mg/g & 5,28 & 4,07 & 4,71 \\
Valor calórico; kcal/100g & 377,08 & 398,91 & 427,53 \\
\hline
\end{tabular}

*Valores determinados por laboratório externo de análises em duplicata; desvios padrões não fornecidos.

O perfil sócio demográfica dos 120 participantes dos testes de aceitação e intenção de compra do biscoito tipo "cookies" a base de torta de amêndoa de Macaúba foi caracterizado por: sexo feminino - 73\%; com idade entre $15-25$ anos - 55,8\%; com ensino superior incompleto $47,5 \%$. Quase metade dos colaboradores $(45 \%)$ que participaram da pesquisa apresentou renda familiar entre um e cinco salários mínimos.

Na Tabela 4 são apresentados os resultados das médias das notas atribuídas às características sensoriais das três amostras avaliadas pelos provadores. Conforme Tabela 2, os resultados obtidos da prova das amostras B e C destacam-se pela predominância das médias localizadas entre os termos hedônicos "gostei ligeiramente" e "gostei moderadamente", representando uma aceitação pela maior parte dos provadores. A amostra A não obteve o mesmo sucesso, localizando-se na faixa de indiferença nas características aparência e aroma. Observa-se que as médias das notas para amostra $\mathrm{A}$ foram menores na maior parte das características em relação às amostras $\mathrm{B}$ e $\mathrm{C}$, exceto pela característica textura em que se observa uma média menor para a amostra $\mathrm{C}$. Estatisticamente as amostras B e C não foram diferentes entre si $(p<0,05)$ em quase todas as características testadas, exceção feita na avaliação da característica textura. Em relação à textura nota-se uma alteração no padrão observado até então entre as outras características, em que as médias mais altas foram atribuídas às amostras $\mathrm{B}$ e $\mathrm{C}$. No caso da textura, a amostra $\mathrm{C}$ teve uma média baixa, em que a provável justificativa é relacionada à redução da umidade do cookie com $60 \%$ de torta de amêndoa, no qual há uma maior concentração de fibras.

Na Tabela 5 é apresentado o resultado contendo as médias das notas de aceitação em relação à intenção de compra dos biscoitos tipo cookies de torta de amêndoa de Macaúba. Os resultados direcionam para a conclusão de que as amostras $\mathrm{B}$ e $\mathrm{C}$ tem um potencial de comercialização maior que a amostra A, o que fortalece a proposição deste trabalho de uso da torta da amêndoa da Macaúba como matéria-prima potencial para uso de produtos na alimentação humana. Vale destacar que o principal objetivo deste teste foi justamente a verificação da utilização da torta da amêndoa da Macaúba em alimentos para o consumo humano, e que a melhor formulação não era o principal destaque deste trabalho. Ainda, a partir dos resultados deste trabalho pode-se prever que com os ajustes necessários no tocante a modificações na formulação para a inclusão de componentes de conhecido gosto por parte da comunidade brasileira, tanto a amostra com 30\% quanto a com $60 \%$ de substituição da farinha de trigo podem ser utilizadas no desenvolvimento de novos produtos. Adicionalmente, um trabalho de marketing com divulgação de características 
buscadas por classes de consumidores, tais como a elevada quantidade de fibras e proteínas presentes nesta torta, certamente direcionará para uma melhor aceitação do produto.

No estado do Mato Grosso do Sul o uso da farinha da polpa da Bocaíuva (nome popular da Macaúba nesse estado) é uma realidade, com destaques aos trabalhos de Damasceno Junior e Souza (2010) e CEPPEC (2008). Cabe ressaltar que a Bocaíuva tem um perfil diferenciado da Macaúba no que se refere ao maior teor de açúcares em detrimento do menor teor de óleo.

Tabela 4 - Resumo das médias das notas de aceitação atribuídas às características sensoriais das três amostras de cookies avaliadas pelos provadores.

\begin{tabular}{|c|c|c|c|c|c|}
\hline & Aparência & Aroma & Sabor & Textura & $\begin{array}{c}\text { Impressão } \\
\text { Global }\end{array}$ \\
\hline Amostra A & $4,1 \pm 2,4^{\mathrm{a}}$ & $4,7 \pm 2,3^{\mathrm{a}}$ & $5,5 \pm 2,5^{\mathrm{a}}$ & $5,7 \pm 2,5^{\mathrm{a}}$ & $5,2 \pm 2,3^{\mathrm{a}}$ \\
\hline Amostra B & $5,5 \pm 2,1^{\mathrm{b}}$ & $6,0 \pm 1,9^{b}$ & $6,4 \pm 2,2^{b}$ & $6,4 \pm 2,1^{\mathrm{b}}$ & $6,2 \pm 1,8^{b}$ \\
\hline Amostra C & $5,5 \pm 2,2^{\mathrm{b}}$ & $6,3 \pm 1,8^{b}$ & $6,6 \pm 2,0^{b}$ & $5,4 \pm 2,4^{\mathrm{a}}$ & $6,1 \pm 1,8^{b}$ \\
\hline
\end{tabular}

Tabela 5 - Médias das notas de aceitação em relação à intenção de compra dos biscoitos tipo "cookies".

\begin{tabular}{cc}
\hline Amostra & Médias $^{*}$ \\
A & $3,0 \pm 1,2^{\mathrm{a}}$ \\
B & $3,6 \pm 1,1^{\mathrm{b}}$ \\
C & $3,4 \pm 1,1^{\mathrm{b}}$ \\
\hline
\end{tabular}

Amostra A: 0\% de torta da amêndoa da Macaúba; Amostra B: 30\% de torta de amêndoa da amêndoa da Macaúba; Amostra C: 60\% de torta da amêndoa de Macaúba. DMS (Diferença Mínima Significativa) = 0,30 *Médias seguidas por letras iguais na coluna não apresentam diferença a 5\% de significância estatística.

O uso da torta da polpa é objeto de desenvolvimentos pelo grupo de pesquisa da UFMG, conforme destacado no trabalho de Veridiano (2012), que substitui de 30\% a 54\% da farinha de trigo pela farinha da torta de polpa da Macaúba para produzir um bolo e obteve satisfatória aceitação dos provadores, conseguindo provar a utilidade deste coproduto da extração do óleo no desenvolvimento de produtos para alimentação humana. Kopper et al (2009) também utilizaram a farinha da polpa da Macaúba em biscoitos tipo cookies doces e salgados, substituindo-se de $10 \%$ a $15 \%$ da farinha de trigo pela farinha de Macaúba. Estes relataram que a aceitação de ambos os produtos foi positiva, apresentando médias correspondentes ao termo hedônico "gostei levemente".

A utilização da amêndoa da Macaúba em alimentação humana, comumente, é na forma in natura, sendo mais difícil ver o aproveitamento da torta proveniente da extração do óleo da amêndoa. Nogueira e outros (2012) elaboraram uma barra de cereais com adição da amêndoa da Macaúba e alcançaram uma intenção de compras de $90 \%$ para este produto, apresentando um alto 
potencial de aceitação e preferência, sendo considerado um produto saboroso e agradável. Dessimoni-Pinto et al (2010) já haviam relatado em trabalho posterior a utilização da amêndoa da Macaúba para elaboração de barras de cereais. Nesse caso, houve uma adição de $15 \%$ do fruto em relação a uma barra controle. No final do trabalho, concluiu-se que a barra teste obteve maior aceitação que a barra controle, destacando-se quanto ao sabor, com nota média de 4,62 em uma escala de 5 pontos. O índice de aceitação foi de 88,90\% e o teste de preferência evidenciou $71,11 \%$ de aprovação pelos participantes da pesquisa.

Os resultados deste trabalho e dos relatados pela literatura indicam que a utilização da farinha obtida da amêndoa da Macaúba na forma in natura ou na forma de torta na elaboração de produtos alimentícios é uma possibilidade que pode ser muito bem aproveitada pelo mercado, principalmente pelas cooperativas que trabalham com este fruto comumente encontrado no Cerrado, com destaque ao baixo custo de processamento e acessibilidade ao pequeno produtor.

\section{CONCLUSÃO}

Os resultados obtidos nas análises de composição centesimal e sensorial indicam que a torta da amêndoa da Macaúba possui um potencial elevado para utilização em alimentos humanos. As amostras B e C confirmam esse potencial, dando maior destaque a aceitação em todas as características pela amostra $\mathrm{B}$, sendo esta amostra avaliada com maior média na intenção de compra. Destaca-se que a única restrição ao uso dessa matéria-prima recai nas condições adequadas de manejo do fruto e processamento, as quais devem atender a legislação vigente.

Conclui-se que a torta da amêndoa da Macaúba pode ser utilizada em alimentos e que apresenta características nutricionais e sensoriais interessantes para a dieta humana.

\section{REFERÊNCIAS}

DESSIMONI-PINTO, N. A. V.; SILVA, V. M.; BATISTA, A. G.; VIEIRA, G.; SOUZA, C. R.; DUMONT, P. V.; SANTOS, G. K. M. Características físico-químicas da amêndoa de Macaúba e seu aproveitamento na elaboração de barras de cereais. Alim. Nutr., v.21, n.1, p. 77-84. Araraquara, SP. Março de 2010.

IEA. Instituto de Economia Agrícola. Agricultura de alimentos versus de energia: impacto nas cotações internacionais. Análises e Indicadores do Agronegócio. Vol.3 n.1. Janeiro de 2008. Disponível em: http://wwwiea.sp.gov.br/out/verTexto.php?codTexto=9167. Acesso em: 23 jul. 2012.

INSTITUTO ADOLF LUTZ. Métodos físico-químicos para análise de alimentos. $4^{\mathrm{a}}$ Ed. São Paulo: Instituto Adolf Lutz, 2008, 1020 p. Versão eletrônica.

KOPPER, A. C.; SARAVIA, A. P. K.; RIBANI, R. H.; LORENZI, G. M. A. C. Utilização tecnológica da farinha de bocaiúva na elaboração de biscoitos tipo cookie. Curitiba, Paraná. Alim. Nutr. Araraquara, v. 20, n. 3, p. 463-469, jul./set. 2009.

LORENZI, G. M. A. C. Acrocomia aculeata (Lodd. ) ex Mart. - ARECACEAE: BASES PARA O EXTRATIVISMO SUSTENTÁVEL. Tese. Programa de Pós-graduação em Agronomia, Universidade Federal do Paraná. Curitiba, 172f. 2006. 
MINIM, V. P. R. Análise Sensorial: estudo com consumidores. 2a Ed. Viçosa: Ed. UFV, 2010. $225 \mathrm{p}$.

NOGUEIRA, L. S.; VIEIRA, J. T. F.; VIROLI, S. L. M. Elaboração de uma barra de cereais contendo amêndoa de Macaúba: uma alternativa econômica para agricultura familiar. São Luís, $64^{\mathrm{a}}$ Reunião Anual as SBPC. Ciência e Tecnologia de Alimentos. Disponível em: http://www.sbpcnet.org.br/livro/64ra/resumos/resumos/10127.htm Acesso: 17 abril 2014.

TACO. Tabela brasileira de composição de alimentos. $4^{\mathrm{a}}$ Ed. rev. e ampl; Campinas: NEPAUNICAMP, 2011. $161 \mathrm{p}$.

VEREDIANO, F. C. Aproveitamento da torta residual da extração do óleo da polpa da Macaúba para fins alimentícios. 114p. Dissertação (Mestrado em Engenharia Química). Escola de Engenharia Química da Universidade Federal Minas Gerais. Belo Horizonte, 2012. 